\title{
GTNP BReEding BIRd Monitoring ProjeCt: THE 1999 SEASON
}

\author{
M.L. CODY $\downarrow$ DEPARTMENT OF BIOLOGY \\ UNIVERSITY OF CALIFORNIA $\uparrow$ LOS ANGELES
}

\section{OVERVIEW: GTNP BREEDING BIRD MONITORING PROJECT:}

1. Following initial independent work by M. L. Cody and $3 y$ funding from NPS, we have instigated a scheme for long-term monitoring of breeding land bird populations in a wide variety of habitats representative of the northern Rockies and the Greater Yellowstone Ecosystem (GYE). Census sites are located almost entirely within Grand Teton National Park, where a broad range of representative vegetation types is accessible within close geographic proximity.

2. Some 30 monitoring sites are established within and adjacent to the park in pristine habitat. Sites range from the Jackson Hole lowlands to subalpine and alpine sites, from meadow, sagebrush and marshland, through willow scrub, cottonwood and aspen woodlands, to lodgepole pine and spruce-fir forests. Some sites have a monitoring history of $>30 \mathrm{y}$; others were established in the mid-1990's.

3. The location and accessibility of the study sites permits all to be regularly and repeatedly censused during the short (6-week) breeding season. Census sites are standardized in area (5-10 ha in size) and mapped in detail (topographic features, vegetation). Census schedules, timing, and methodological protocols will be established and maintained, providing for strictly controlled inter-site and inter-year comparisons in breeding bird populations, species composition, and densities.
4. To evaluate the local versus more regional nature of inter-year variation in bird densities, one widespread habitat (willows) is replicated and censused at locations outside GTNP, in the northern Rockies (Glacier National Park) and central Rockies (Rocky Mountain National Park).

5. The project entails only modest costs (e.g. for transportation), but the projected benefits to science, specifically to resource management, will continue to accumulate as the data base is expanded in future years. As no comparable data base or monitoring scheme exists for the region, the value of the GTNP is apparent, and ensuring its continuance is of critical importance.

\section{SEASON: COVERAGE AND PARTICIPANTS}

Participants. Seven persons* participated in the 1999 census effort, although pre-season attempts to engage a large body of participants were made.

*Martin L. Cody \& Greg Schrott, Dept. Organismic Biology, Ecology \& Evolution, UCLA Mary Ann Harlow, UW-NPS Research Station Matt Killebrew \& Sue Wolff, Moose, WY Susan Patla, Wyoming Game and Fish Dept, Jackson, WY

Ron Steffens, Southwestern Oregon Community College, Coos Bay, OR

Site Coverage. Nineteen of the 30 monitoring sites were assessed in 1999. Coverage was continued on those sites with the longest 
monitoring history, which in some cases covers several decades; coverage also spanned the full habitat range of GTNP's monitoring sites (see table below).

The last column of the above table indicates the sites to which we have assigned priority for the 2000 season; the selection is a compromise between unbroken continuity at important "flagship" sites and the advantage of extending coverage of less routinely censused areas. It is envisaged that, in order to cover this list of priorities, we will again need the assistance of a number of volunteers; attempts to elicit interest in the monitoring program among the capable and active birders of Jackson Hole will continue.
The 1999 Censuses. The list of breeding species at the monitoring sites was extended to 150 , with the inclusion of White-winged Crossbill at Site 27: Rendezvous Mountain spruce-fir. Overall, breeding densities were much like those of 1998, as illustrated in the following 15 summary figures. Detailed analyses of warblers and emberizine sparrows in Site 10: Jackson Lake Junction Wet willows was published P. Keddy \& E. Wieher (eds), Ecological Assembly Rules, Cambridge Univ. Press 1999. Several of the lodgepole pine monitoring sites are a part of G. Shrott's dissertation research which is currently in the writing stage.

\begin{tabular}{|c|c|c|c|c|c|c|c|c|c|c|c|c|c|}
\hline \multicolumn{14}{|c|}{ COVERAGE OF GTNP BREEDING BIRD MONITORING SITES, 1966-2000 } \\
\hline & & & & & & & & & & & & Tot & Yr 2000 \\
\hline Site/Census'd & 66 & 91 & 92 & 93 & 94 & 95 & 96 & 97 & 98 & 99 & Who & Yrs & \\
\hline 1:Wolf Rch & & & 1 & 1 & 1 & 1 & 1 & 1 & & & & 6 & 1 \\
\hline 2:JLJ Sedge & & & 1 & 1 & 1 & 1 & 1 & 1 & 1 & 1 & $\mathrm{mlc}$ & 7 & 1 \\
\hline 3:Elk Refuge & & & & & 1 & 1 & 1 & 1 & 1 & 1 & spat & 5 & 1 \\
\hline 4:JLJ Gr-sage & 1 & 1 & 1 & 1 & 1 & 1 & 1 & 1 & 1 & 1 & $\mathrm{mlc}$ & 9 & 1 \\
\hline 5: Ant.Flats & & & & & & 1 & 1 & 1 & & 1 & ron & 3 & 1 \\
\hline 6: Airpt Sage & & & & 1 & 1 & 1 & 1 & 1 & 1 & & & 6 & 1 \\
\hline 7: 2OL Meadou & & & & 1 & 1 & 1 & 1 & 1 & 1 & 1 & gs & 6 & \\
\hline 8:Triangle $\mathrm{X}$ & & & & & & & 1 & 1 & & & & 2 & \\
\hline 9: RKO & & & & 1 & 1 & 1 & 1. & 1 & 1 & 1 & $\mathrm{mlc}$ & 6 & 1 \\
\hline 10:JLJ Will & 1 & 1 & 1 & 1 & 1 & 1 & 1 & 1 & 1 & 1 & $\mathrm{mlc}$ & 9 & 1 \\
\hline 11: Oxbow & & & & 1 & 1 & 1 & 1 & 1 & 1 & 1 & $\mathrm{mlc}$ & 6 & 1 \\
\hline 12: Elk Rch W & 1 & & 1 & 1 & 1 & 1 & 1 & 1 & & & & 7 & 1 \\
\hline 13: Elk Rch E & 1 & & 1 & 1 & 1 & 1 & 1 & 1 & 1 & & & 8 & 1 \\
\hline 14: Cow Lk & 1 & & 1 & 1 & 1 & 1 & 1 & 1 & & 1 & ron & 7 & \\
\hline 15: Spread Ck & & & 1 & 1 & 1 & 1 & 1 & 1 & 1 & & & 7 & 1 \\
\hline 16: Schwabch & & & 1 & 1 & 1 & 1 & 1 & 1 & & 1 & matt/sue & 6 & \\
\hline 17: L. Granite & & & & & & 1 & 1 & 1 & & & & 3 & \\
\hline 18: Timbered Is & & & & & 1 & 1 & 1 & 1 & 1 & 1 & ron & 5 & \\
\hline 19: AMK & & & 1 & 1 & 1 & 1 & 1 & 1 & 1 & 1 & gs & 7 & 1 \\
\hline 20: TaggartLk & & & & & 1 & 1 & 1 & 1 & 1 & & & 5 & 1 \\
\hline 21: Signal Mt & & & 1 & 1 & 1 & 1 & 1 & 1 & 1 & 1 & gs & 7 & \\
\hline 22: Spaulding & & & & & & 1 & 1 & 1 & & & & 3 & \\
\hline 23: LizardCk & & & 1 & 1 & 1 & 1 & 1 & 1 & & & & 6 & 1 \\
\hline 24: Bradley & & & & & 1 & 1 & 1 & 1 & & & & 4 & 1 \\
\hline 25:JennyLk & & & & 1 & 1 & 1 & 1 & 1 & 1 & 1 & matt/sue & 6 & 1 \\
\hline 26:GranSpruce & & & & & 1 & 1 & 1 & 1 & & 1 & matt/sue & 4 & \\
\hline 27:Rendezvous & & & & & 1 & 1 & 1 & 1 & & 1 & matt/sue & 4 & \\
\hline 28:CodyBowl & & & & & 1 & 1 & 1 & 1 & & 1 & matt/sue & 4 & \\
\hline 29:HeronLk & & & & & & 1 & 1 & 1 & & 1 & maryann & 3 & \\
\hline 30:Blacktail & & & & & & & 1 & 1 & & 1 & matt/sue & 2 & \\
\hline Total Sites: & 5 & 2 & 12 & 17 & 24 & 28 & 30 & 30 & 15 & 19 & Ave: & 5.7 & Tot: 17 \\
\hline
\end{tabular}


Sit e 2: JLJ Grass-sedge

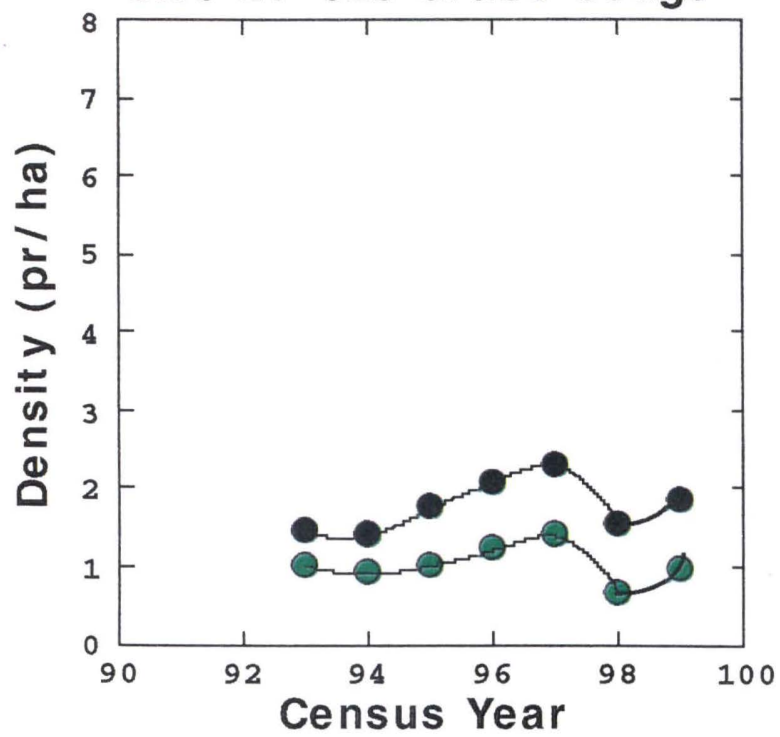

Site 4 : JLJ Grass-sage

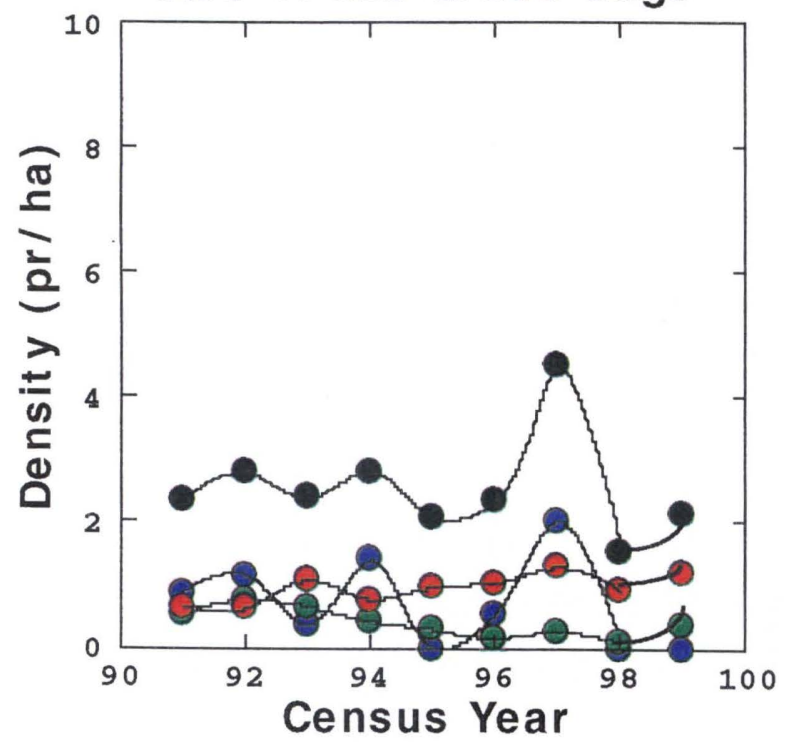

Site 3: Elk Refuge Wet Meadow

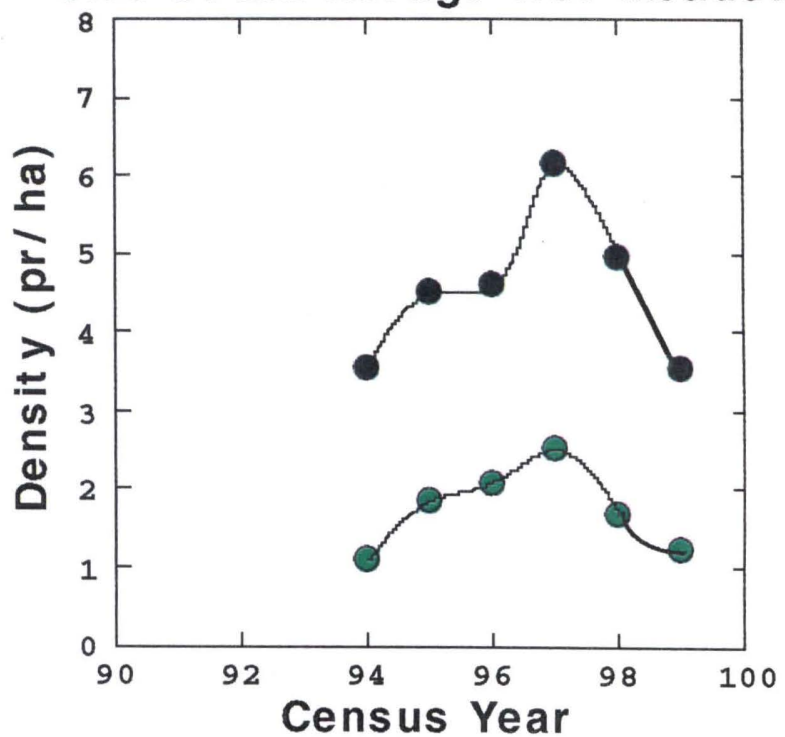

Site 6: Airport Sage

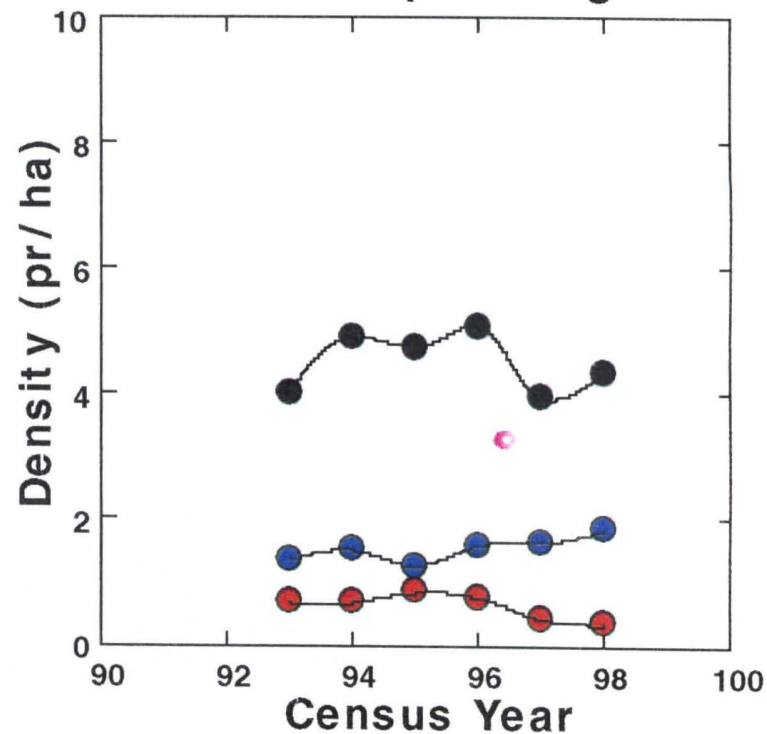

Site 7: Two Ocean Lake Meadow

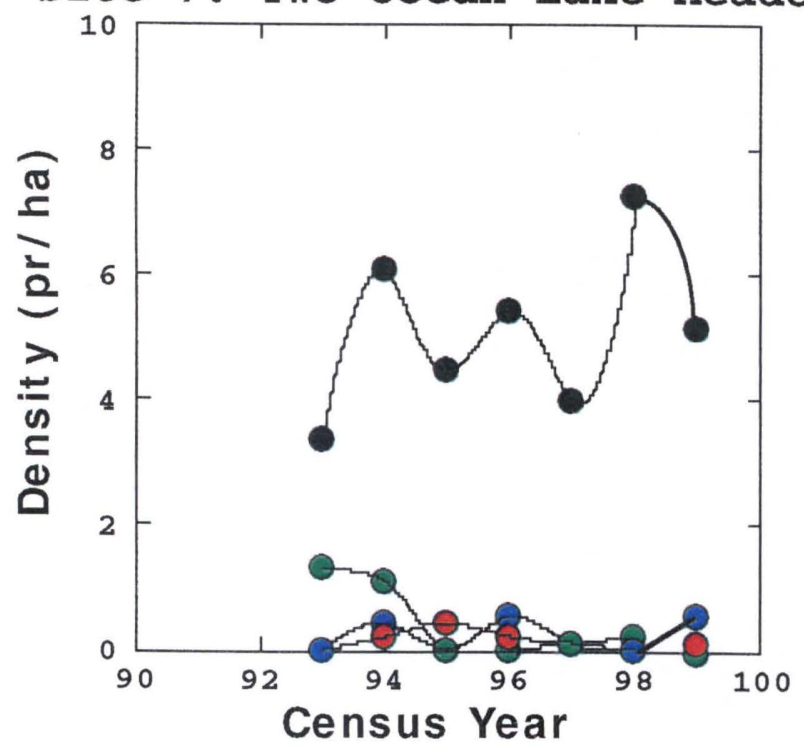

All species

- Savannah Sparrow

- Vesper Sparrow

- Brewer's Sparrow 

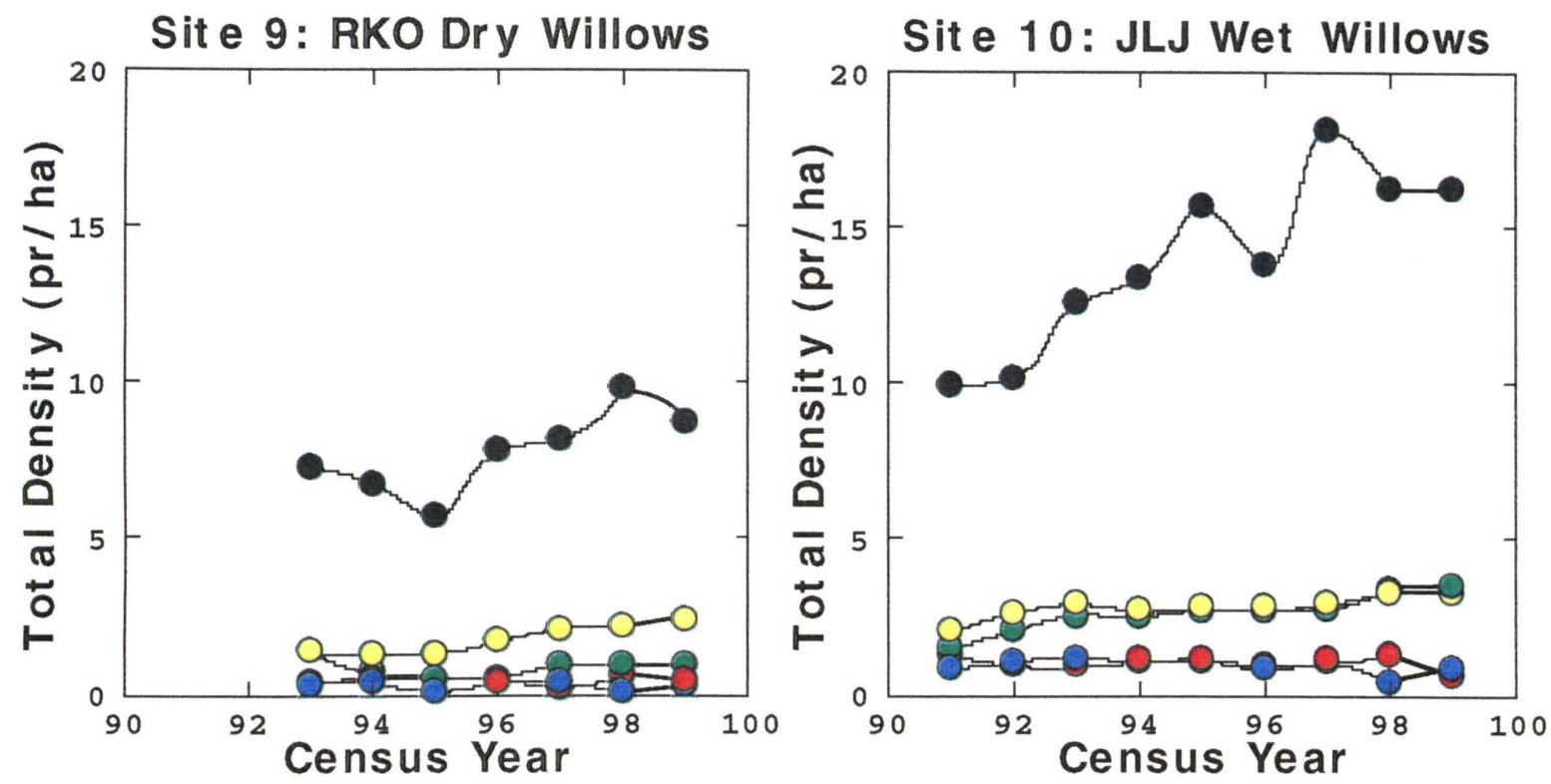

Site 11: Oxbow Willow-aspen
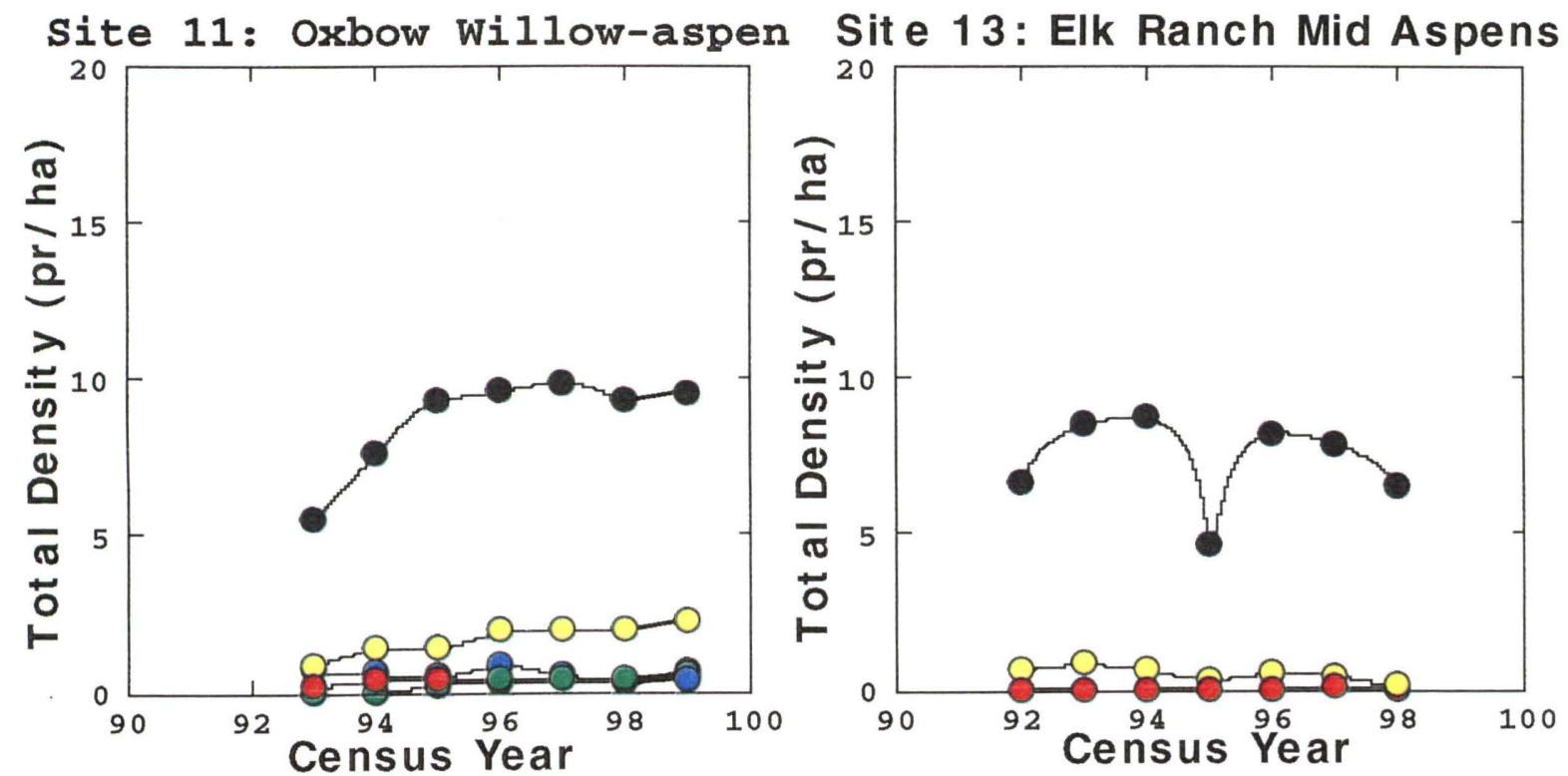

Site 15: Spread Ck Cot t onwoods

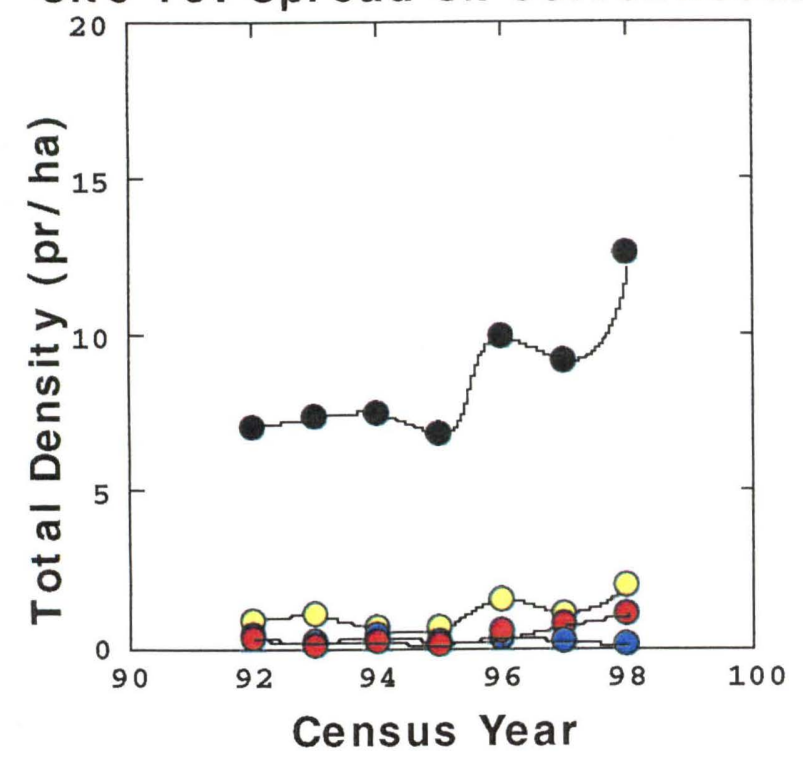

- Tot al Bird Density

- Yellow Warbler

- C. Yellowt hroat

- Lincoln's Sparrow

- Fox Sparrow 
Site 18: Timbered Is Lodgepole
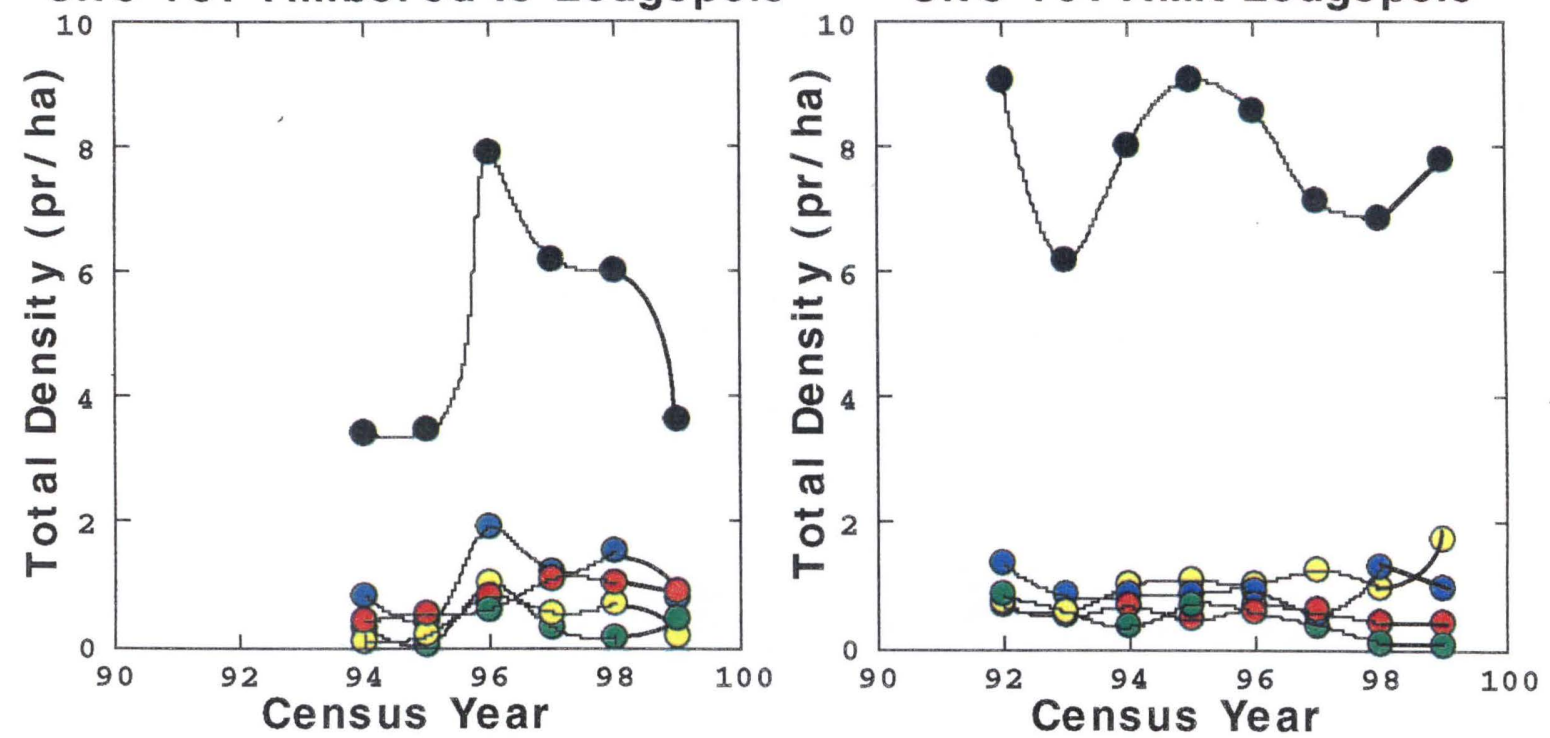

Site 20: Taggart Lake Burn

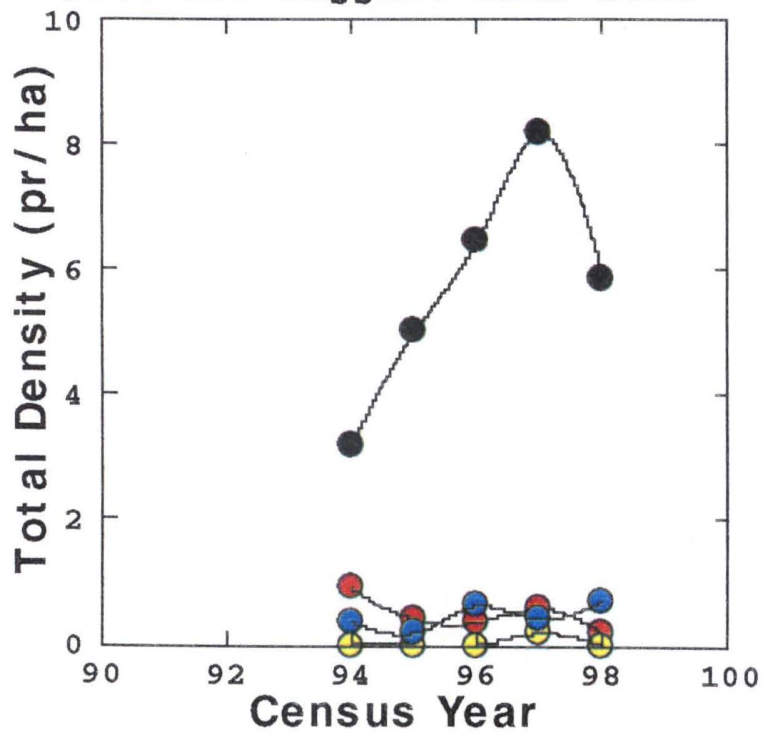

Sit e 21 : Signal Mt Lodgepole-Spruce

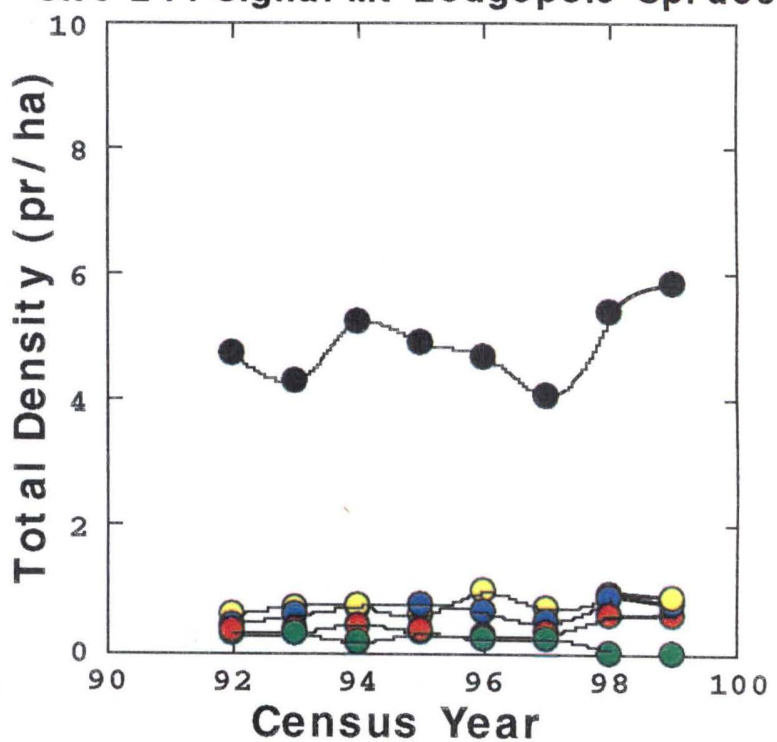

Site 25: Jenny Lake Spruce-Fir

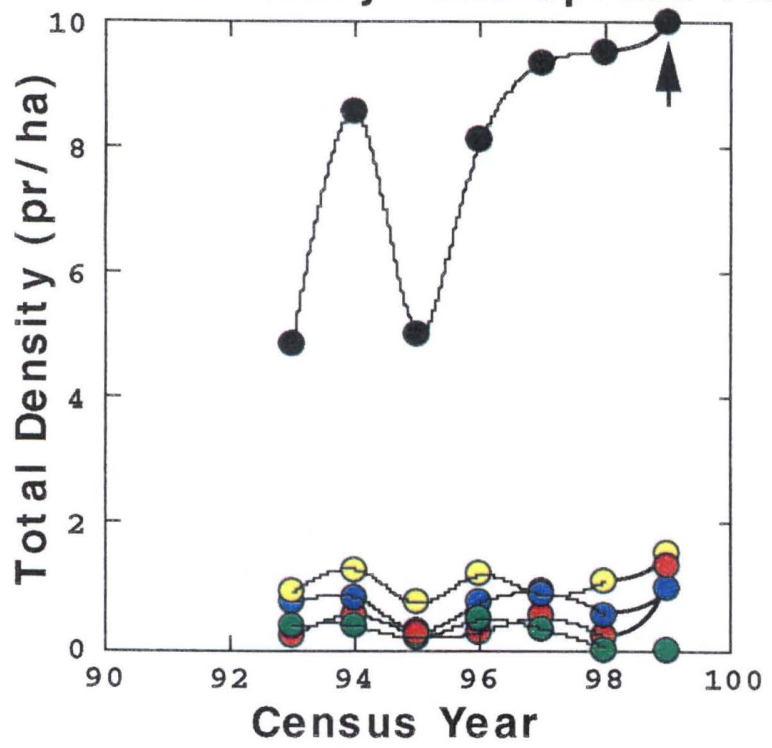

Tot al Bird Densit y

- Yellow-rumped Warbler

- Dark-eyed Junco

- Chipping Sparrow

- Ruby-crowned Kinglet 